\title{
Evidence for sibling species in Cryptocercus punctulatus, the wood roach, from variation in mitochondrial DNA and karyotype
}

\author{
SRINIVAS KAMBHAMPATI*, PETER LUYKX $† \&$ CHRISTINE A. NALEPA $\ddagger$ \\ Department of Entomology, Kansas State University, Manhattan, KS 66506, †Department of Biology, University of \\ Miami, Coral Gables, FL 33124 and $\ddagger$ Department of Entomology, North Carolina State University, Raleigh, NC 27695, \\ U.S.A.
}

\begin{abstract}
The wood-feeding genus Cryptocercus is considered the basal lineage among extant cockroaches. Cryptocercus is the sole representative of the family Cryptocercidae and at present three species are recognized within the genus worldwide: Cryptocercus punctulatus in the United States, $C$. relictus in Eurasia and $C$. primarius in the Orient. The geographical distribution of $C$. punctulatus in the USA is disjunct, with populations occurring along the Appalachian Mountains and in the Pacific North-west. In samples collected from several locations of the eastern and the western USA, we investigated variation in DNA sequence of portions of the two mitochondrial rRNA genes and in chromosome number. The overall sequence divergence among 30 individuals assayed from 17 locations was 17.3 per cent. A phylogenetic analysis revealed that in the east, individuals in Virginia had diverged significantly in their haplotype from those in North Carolina, Georgia and Alabama; individuals in the west (Oregon) had diverged in their haplotype from individuals in the east. The diploid chromosome number for 52 male $C$. punctulatus sampled from 15 locations varied from $37\left(18^{\mathrm{II}}+\mathrm{X}\right)$ to $47\left(23^{\mathrm{II}}+\mathrm{X}\right)$. In the eastern samples, the diploid chromosome number ranged from 37 to 45 , whereas in Oregon all individuals had $2 n=47$. No polymorphism in DNA sequence or chromosome number among individuals collected within a locality was detected. The DNA sequence and chromosome number variation data, together with preliminary studies on mating incompatibility, strongly suggest that $C$. punctulatus in the USA is comprised of at least two and probably three sibling species, with one species occurring in western USA and one or more species in eastern USA.
\end{abstract}

Keywords: chromosomal races, Cryptocercus punctulatus, genetic variation, mitochondrial DNA, sibling species.

\section{Introduction}

The xylophagous genus Cryptocercus (Dictyoptera: Blattaria: Cryptocercidae) is considered the basal lineage among extant cockroaches (McKittrick, 1964; Kambhampati, 1995). This genus is the sole representative of the family Cryptocercidae and consists of three species worldwide: Cryptocercus punctulatus in the USA, $C$. relictus in Eurasia and $C$. primarius in the Orient. The biology of $C$. punctulatus was reviewed by Nalepa (1994). Cryptocercus is

\section{*Correspondence.}

This paper is dedicated to Dr George W. Byers, University of Kansas, in recognition of his many contributions to insect systematics. unique among cockroaches in harbouring intestinal flagellates that enable the digestion of cellulose. All species feed on rotting wood and $C$. punctulatus and C. relictus are known to live in family groups (Mamaev, 1972). The taxonomic position of Cryptocercus and its relationship to the termite, Mastotermes darwiniensis, have been the subjects of recent debates (reviewed by Kambhampati, 1995).

The geographical distribution of $C$. punctulatus in the USA is disjunct, with populations occurring in the Appalachian Mountains in several eastern states and in the Pacific North-west (Fig. 1a). In light of the disjunct distribution, we initiated studies to quantify patterns of genetic variation and mating incompatibility among samples collected in various 
locations. In this paper, we report on DNA sequence variation in portions of the mitochondrial small and large ribosomal subunit genes, variation in chromosome number, and preliminary results of mating studies. The results we have obtained strongly suggest that what is presently recognized as C. punctulatus consists of a sibling species complex, with two or more species occurring in the USA.

\section{Materials and methods}

\section{Insects}

Individuals of $C$. punctulatus were collected from 20 locations in eastern USA and Oregon between 1987 and 1994 (Fig. 1b; Table 1). The insects were either dissected for karyotype analysis, placed in 70 per cent ethanol for molecular analysis, or transported live to Mountain Lake Biological Station, Giles County, VA, for mating studies. The cockroaches were collected from rotted pine and hardwood logs in the east and from rotted Douglas fir logs in Oregon. For the molecular and karyotype analyses, one or more individuals were taken from each location; usually, two to three individuals were collected from different but nearby logs, and therefore were probably from different family groups. Insects from Oregon were treated as a group for the mating studies. All Virginia insects for mating studies were collected within $\mathrm{a} \approx 6 \mathrm{~km}$ radius of Mountain Lake Biological Station.

\section{PCR, DNA sequencing and oligonucleotide primers}

Procedures for DNA extraction, polymerase chain reaction (PCR) and DNA sequencing were described by Kambhampati et al. (1992) and Kambhampati (1995). Both strands of the amplified PCR product were sequenced directly using the cycle sequencing method (fmol Sequencing System, Promega Corp., Madison, WI). The primers for the amplification and sequencing of the $\approx 410 \mathrm{bp}$ portion of the $16 \mathrm{~S}$ rRNA gene were as follows: forward, 5'-TTACGCTGTTATCCCTAA-3' (positions 13000- 13017 of Drosophila yakuba) and reverse, 5'-CGCCTGTTTATCAAAAACAT-3' (13 396-13 415). The primers for the amplification and sequencing of the $\approx 440 \mathrm{bp}$ portion of the $12 \mathrm{~S}$ rRNA gene were as follows: forward, 5'TACTATGTTACGACTTAT-3' (14 182-14 199) and reverse, 5'-AAACTAGGATTAGATACCC-3' (14594-14612). The forward primers of both sets were designed by Kambhampati (1995) and Kambhampati \& Smith (1995), and the reverse primers designed by Simon (1991).

\section{Sequence alignments and phylogenetic inference}

The sequences were read from autoradiographs into a computer and aligned using CLUSTAL V (Higgins \& Sharp, 1989). The alignment parameters were $k$-tuple score $=1$, gap penaity $=3$ and window size $=5$ (pairwise alignments); fixed and floating gap penalties $=10$ (multiple alignments). The computergenerated alignments were then optimally aligned manually. Phylogenetic analysis was carried out using the multiple equally parsimonious heuristic search option with the tree bisection-reconnection algorithm of PAUP 3.1.1 (Swofford, 1993) with 100 random addition replicates. Neighbour-joining analysis (Saitou \& Nei, 1987) based on Kimura 2-parameter distances (Kimura, 1980) was carried out using MEGA 1.01 (Kumar et al., 1993). For both parsimony and distance analyses, the sequences of the two genes were analysed as a single data set

(a)

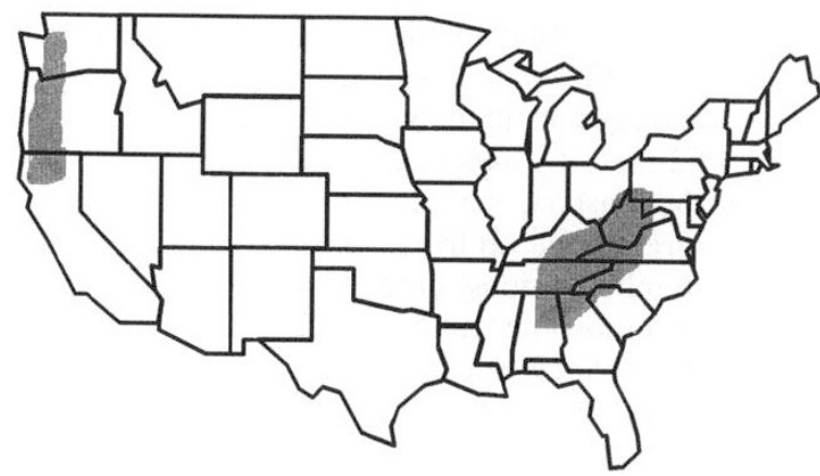

(b)
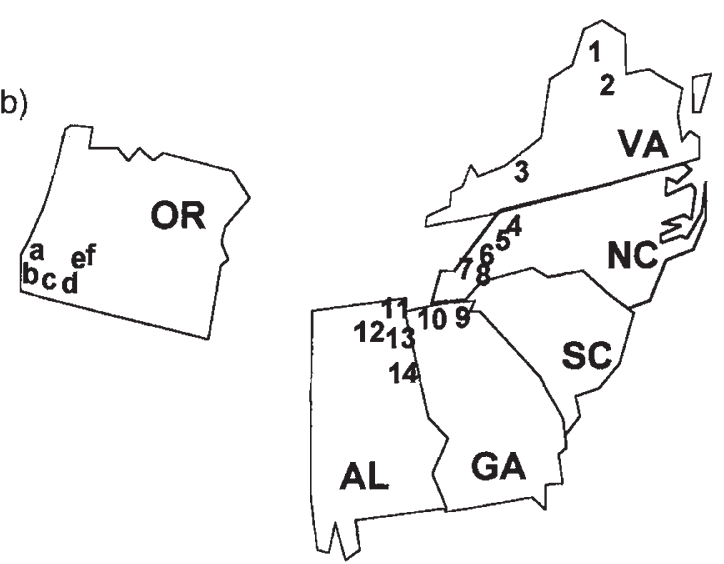

Fig. 1 (a) The distribution of Cryptocercus punctulatus in the United States (shaded areas; redrawn from Atkinson et al., 1991). (b) A map of the five eastern states and Oregon showing the locations from which samples of $C$. punctulatus were collected. The numbers and letters correspond to locations given in Table 1.

(c) The Genetical Society of Great Britain, Heredity, 76, 485-496. 
without character weighting and gaps were treated as fifth base. Bootstrap analysis was undertaken with 1000 replications for parsimony analysis and 500 replications for the distance analysis. DNA sequences of homologous fragments of the $16 \mathrm{~S}$ and 12S rRNA genes of Blatta orientalis and Periplaneta americana (Blattidae), and of Blaberus atropos (Blaberidae), previously published by Kambhampati (1995), were included as outgroups. The sequences reported in this paper can be obtained from the GenBank database under accession numbers U38380-U38413 or from S.K.

\section{Karyotype analysis}

For the karyotype studies, a total of 52 individual insects were collected from 15 locations, including many of the same locations used for mtDNA studies (Table 1). Meiotic and mitotic chromosomes from testes of males and mitotic chromosomes from follicle cells in ovaries of females were examined as described by Luykx (1983). Karyotypes are given here either in terms of male haploid (meiotic) complements (e.g. $18^{\mathrm{II}}+\mathrm{X}=18$ autosomal bivalent$\mathrm{s}+$ one $\mathrm{X}$ chromosome) or as the diploid (mitotic) complement (e.g. 37 chromosomes). The corresponding female complement (with two $\mathrm{X}$ chromosomes) is one more than the male, e.g. $2 n \hat{\delta}=37$, $2 n$ 우 $=38$.

\section{Mating studies}

Virgins were obtained by placing same-sex groups of subadults into field boxes (described by Nalepa, 1988). Boxes were left outdoors at the Mountain Lake Biological Station until the following autumn, when virgin adults were obtained. These were then paired in appropriate combinations and placed in

Table 1 List of locations in which Cryptocercus punctulatus individuals were collected. Also shown are the sample sizes for DNA sequence and chromosomal analysis and chromosome numbers

\begin{tabular}{|c|c|c|c|c|}
\hline \multirow[b]{2}{*}{ Location } & \multirow[b]{2}{*}{$\begin{array}{l}\text { Date } \\
\text { collected }\end{array}$} & \multicolumn{2}{|c|}{ No. individuals sampled } & \multirow[b]{2}{*}{$\begin{array}{c}\text { Chromosome } \\
\text { no. } \dagger\end{array}$} \\
\hline & & $\begin{array}{l}\text { Sequence } \\
\text { analysis }\end{array}$ & Karyotype & \\
\hline \multicolumn{5}{|l|}{ Virginia } \\
\hline 1. Powell Gap & June 1993 & 1 & 2 & 43 \\
\hline 2. Dripping Rock & June 1993 & 1 & 2 & 43 \\
\hline 3. Mountain Lake Biological Station & August 1987 & 2 & 8 & 43 \\
\hline \multicolumn{5}{|l|}{ North Carolina } \\
\hline 4. Crossnore & October 1988 & & 3 & 43 \\
\hline 5. Todd & May 1991 & & 4 & 43 \\
\hline 6. Asheville & June 1994 & 1 & 2 & 45 \\
\hline 7. Swain County & October 1994 & 2 & & \\
\hline 8. Highlands & September 1990 & 1 & 18 & 37 \\
\hline \multicolumn{5}{|l|}{ Georgia } \\
\hline 9. Black Rock Mountain & February 1993 & 2 & 1 & 39 \\
\hline 10. Cherry Log & June 1994 & 1 & 1 & 39 \\
\hline \multicolumn{5}{|l|}{ Alabama } \\
\hline 11. Mentone & June 1994 & 2 & & \\
\hline 12. Lake Guntersville & June 1994 & 1 & 1 & 37 \\
\hline 13. Little River Canyon Park & June 1994 & 2 & 2 & 37 \\
\hline 14. Cheaha State Park & June 1994 & 1 & 2 & 37 \\
\hline \multicolumn{5}{|l|}{ Oregon } \\
\hline a. Glendale, Josephine County & August 1987 & 3 & & \\
\hline b. Selma & August 1987 & 3 & & \\
\hline c. Cave Junction, Jackson County & August 1987 & 3 & 3 & 47 \\
\hline d. Forest Service Road 4611 & August 1987 & 1 & & \\
\hline e. Union Creek & August 1987 & 3 & 2 & 47 \\
\hline f. Mammoth Pines & August 1987 & & 1 & 47 \\
\hline
\end{tabular}

$\uparrow$ The chromosome numbers are the diploid number for males (number of autosomal bivalents plus one X chromosome). The diploid number for females is the male diploid number plus 1 (females have two $\mathrm{X}$ chromosomes). 
boxes. The following autumn the paired insects were checked for survival and reproduction. Boxes in which one or both adults had died were removed from the study. In cases where the female was the surviving member of a cross, she was dissected and her spermatheca examined for the presence of sperm. Intact pairs in which reproduction had not occurred were returned to the field; this procedure was repeated yearly until all insects had either died or reproduced. Crosses therefore required a minimum of two years to complete and could take five years until final results were obtained.

\section{Results}

\section{DNA sequence variation}

A total of 30 individuals from 17 locations were evaluated for DNA sequence variation in portions of the two mitochondrial rRNA genes (Table 1). The size of the sequenced 16S rRNA fragment for the $C$. punctulatus individuals ranged from 406 to $414 \mathrm{bp}$ and that of the $12 \mathrm{~S}$ rRNA fragment was invariant at $440 \mathrm{bp}$. Alignment of sequences of both genes from the 30 individuals resulted in a total of 860 characters, including gaps. Of these, 149 (17.3 per cent) were variable and 100 (11.6 per cent) were parsi- mony-informative. Various statistics for the sequenced portions of the two rRNA genes are summarized in Table 2.

Pairwise Kimura 2-parameter distances and absolute nucleotide differences among individuals from the various locations are given in Table 3. In those cases in which multiple individuals were assayed from a location, the DNA sequences of both gene fragments were identical. Therefore, phylogenetic analyses were carried out with the sequence of one individual from each of the 17 locations.

Parsimony analysis identified two equally parsimonious trees, each of 693 steps: a 50 per cent majority rule consensus of these two trees is shown in Fig. 2. Among samples from the Appalachian Mountains, individuals from North Carolina, Alabama and Georgia were most closely related to one another, followed by those from Virginia. The individual from Asheville was not grouped with individuals from the other two North Carolina locations. The individuals from Oregon formed a separate clade. Most relationships were supported in a majority of the bootstrap replications (Fig. 2). The topology of the neighbour-joining tree (not shown) was nearly identical to that of the tree based on parsimony. The only difference between the two trees was in the position of the individual from

Table 2 Summary statistics for the DNA sequences of the mitochondrial ribosomal RNA genes. The statistics represent the means for 17 individuals of Cryptocercus punctulatus

\begin{tabular}{|c|c|c|}
\hline & $16 \mathrm{~S}$ rRNA & 12S rRNA \\
\hline \multicolumn{3}{|l|}{ Base composition (mean \%) } \\
\hline Adenine & 42.99 & 44.95 \\
\hline Cytosine & 17.30 & 16.23 \\
\hline Guanine & 10.15 & 9.91 \\
\hline Thymine & 29.56 & 28.92 \\
\hline \multicolumn{3}{|l|}{ Transition rate (\%) } \\
\hline Overall & 3.03 & 2.21 \\
\hline $\mathrm{C} \leftrightarrow \mathrm{T}$ & 70.65 & 69.67 \\
\hline$A \leftrightarrow G$ & 29.35 & 30.33 \\
\hline \multicolumn{3}{|l|}{ Transversion rate (\%) } \\
\hline Overall & 4.30 & 3.04 \\
\hline $\mathrm{A} \leftrightarrow \mathrm{C}$ & 16.18 & 26.87 \\
\hline$A \leftrightarrow T$ & 74.50 & 70.34 \\
\hline $\mathrm{G} \leftrightarrow \mathrm{C}$ & 3.80 & 0.46 \\
\hline $\mathrm{G} \leftrightarrow \mathrm{T}$ & 5.52 & 2.33 \\
\hline \multicolumn{3}{|l|}{ Characters } \\
\hline Total (including gaps) & 418 & 442 \\
\hline Variable & $81(19.3 \%)$ & $68(15.3 \%)$ \\
\hline Invariable & $337(80.7 \%)$ & $374(84.7 \%)$ \\
\hline Parsimony informative & $61(14.6 \%)$ & $39(8.8 \%)$ \\
\hline
\end{tabular}




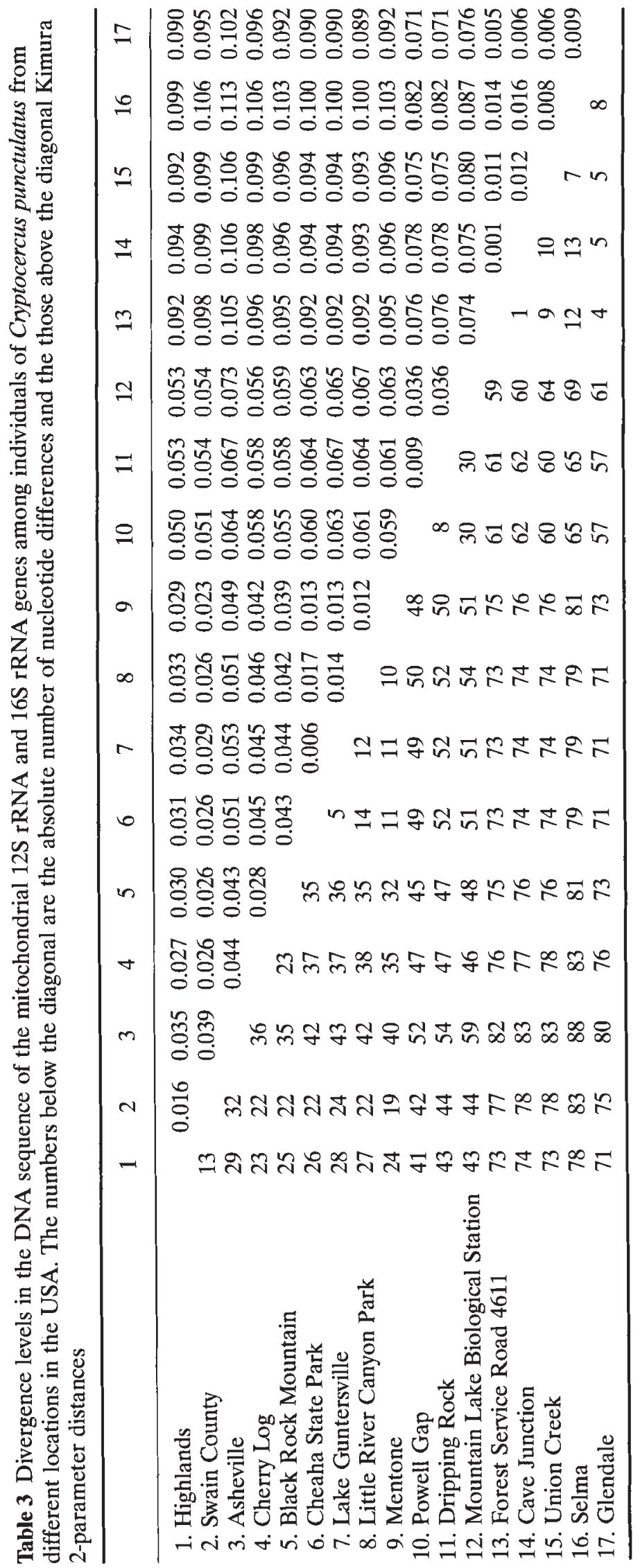




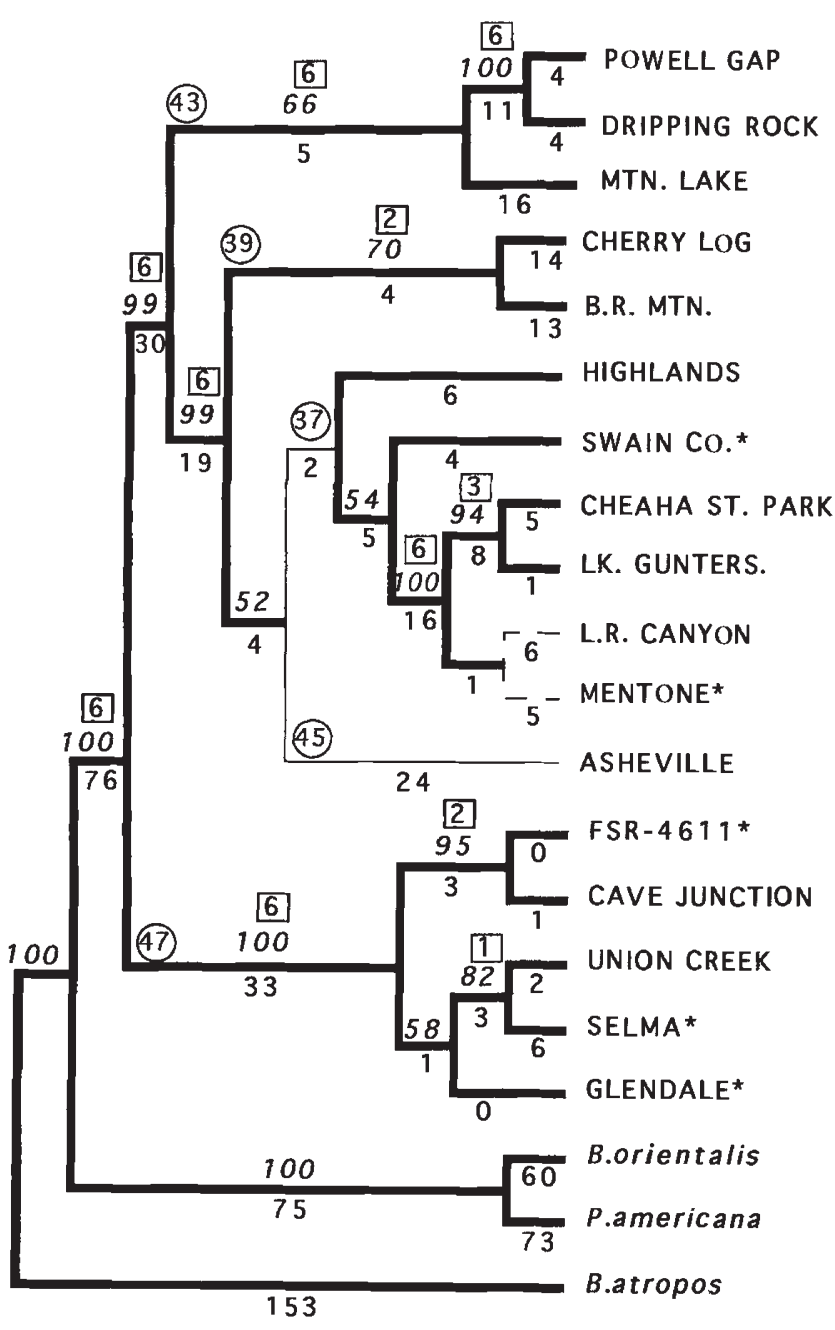

Fig. 2 A phylogenetic tree derived from parsimony analysis of $12 \mathrm{~S}$ rRNA and 16S rRNA gene sequences of Cryptocercus punctulatus rooted by the outgroups Blatta orientalis, Periplaneta americana and Blaberus atropos. Tree length: 693 steps; consistency index: 0.79 ; retention index: 0.83 . The numbers below the branches indicate branch lengths; numbers above the branches indicate the percentage times a branch was recovered in the bootstrap analysis. The branches drawn in bold were supported in $>50$ per cent of the 1000 bootstrap replications; the branch drawn in dotted lines was supported in one of the two equally parsimonious trees. The numbers enclosed in circles represent the diploid chromosome numbers for male $C$. punctulatus. Numbers enclosed in boxes are decay indices which indicate that a particular node was supported in trees that were longer than the most parsimonious tree by the number of steps indicated (Bremer, 1988, 1994) and thus represent progressively relaxed parsimony. Locations marked by an asterisk are those for which the chromosome number was not determined. See Table 1 for location and collection details.
Asheville. In the parsimony analysis, this individual was most closely related to individuals from Alabama and North Carolina whereas in the neighbour-joining tree, the Asheville individual was joined to a clade consisting of individuals from Alabama, North Carolina and Georgia. A bootstrap analysis of 500 replications indicated strong support for most of the inferred relationships.

\section{Karyotype variation}

In all males studied, the first meiotic division showed, depending on the location, from 18 to 23 bivalents and a single, unpaired heterochromatic $\mathrm{X}$ chromosome. Where examined, the mitotic cells of females had an additional chromosome relative to the mitotic cells of males from the same location.

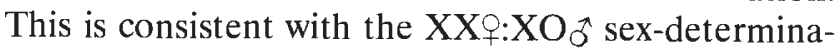
tion system characteristic of cockroaches (Cohen \& Roth, 1970).

The diploid chromosome number for males ranged from 37 in Alabama to 47 in Oregon (Table 1 and Fig. 3). Chromosome numbers were not distributed randomly over the geographical range. In eastern USA, the lower chromosome numbers tended to occur in the southern Appalachians, and the higher chromosome numbers in the more northerly regions. Chromosome numbers from adjacent geographical regions tended to be similar to one another.

\section{Mating studies}

The results of the inter- and intrapopulation crosses are summarized in Table 4. Mating and oviposition in crosses between Virginia females and Oregon males had taken place, but the resulting egg cases were nonviable. In the reciprocal cross, we detected neither mating nor oviposition, although two pairs lived for 3 years after initial pairing. The control Oregon pairs survived 2-3 years after being placed in the field at Mountain Lake Biological Station in Virginia, but 10 out of 13 pairs ( 77 per cent) did not reproduce, perhaps because of a suboptimal environment. All three pairs that reproduced did so in the first year after pairing. In the control Virginia pairs, three pairs reproduced during the first year after pairing, five in the second year and one in the third year.

\section{Discussion}

We have shown that considerable variation in mtDNA and karyotype exists among individuals of 
Fig. 3 Distribution of chromosome numbers of Cryptocercus punctulatus collected in four eastern states and Oregon. The chromosome numbers are for males and represent the number of autosomal pairs plus the $\mathrm{X}$ chromosome. The locations in each state are given in Table 1 and Fig. 1. See text for further details.

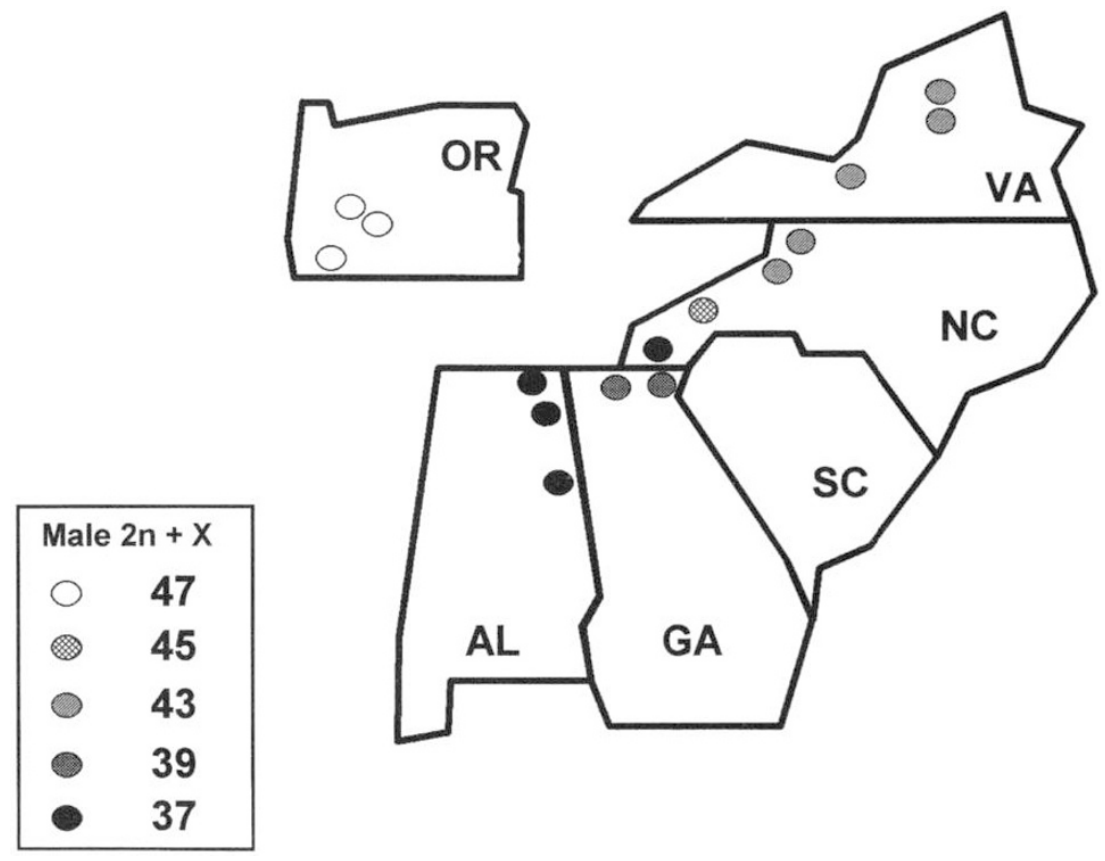

Table 4 Results of crosses between Oregon (OR) and Virginia (VA) Cryptocercus punctulatus individuals. All crosses were performed at the Mountain Lake Biological Station, VA

\begin{tabular}{lccccc}
\hline+ & $\hat{\sigma}$ & $\begin{array}{c}\text { No. pairs } \\
\text { crossed }\end{array}$ & $\begin{array}{c}\text { No. pairs } \\
\text { reproduced }\end{array}$ & $\begin{array}{c}\text { No. pairs died } \\
\text { without reproducing }\end{array}$ & $\begin{array}{c}\text { Evidence of } \\
\text { mating }(n)\end{array}$ \\
\hline OR & VA & 16 & 0 & 16 & No (5) \\
VA & OR & 20 & $5 \dagger$ & 15 & Yes (5), No (3) \\
VA & VA & 11 & 9 & 2 & \\
OR & OR & 13 & 3 & 10 & \\
\hline
\end{tabular}

$†$ Nonviable egg cases.
C. punctulatus collected in various locations of the USA. Below, we discuss the implications of the patterns and levels of genetic variation for the taxonomic status of $C$. punctulatus.

\section{DNA sequence variation}

Previous studies on insects that have utilized the DNA sequence of mitochondrial rRNA genes have found little or no variation among individuals of a species (see Simon et al., 1994, for a review). For example, Fang et al. (1993), who sequenced a 550 bp portion of the 16S rRNA gene (including the portion sequenced for this study) from several leafhoppers, found no sequence divergence among three individuals of Exitianus exitiosus collected in Kansas and New Mexico. Among three species of the genus Graminella, Fang et al. (1993) found 14.6 per cent sequence divergence with a mean Kimura 2-parameter distance $( \pm \mathrm{SE})$ of $0.12 \pm 0.014$. DNA sequence analysis of a portion of the 16S rRNA gene from individuals of Aphidius rosae, a wasp of the family Aphidiidae, collected in Kansas and Germany did not reveal any variation (S. Kambhampati, unpublished observations). DNA sequence analysis of the $16 \mathrm{~S}$ rRNA and the $12 \mathrm{~S}$ rRNA genes (portions homologous to the ones used in this study) of aphids of the family Lachnidae also did not reveal any intraspecific variation (S. Kambhampati, unpublished observations). Moreover, recently diverged species often show low levels of sequence divergence in the mitochondrial rRNA genes. Thus, mitochon- 
drial rRNA genes are not considered good candidates for estimating phylogeny of recently diverged species (Simon et al., 1994). In contrast, the observed level of sequence divergence in portions of the two rRNA genes among 30 individuals of $C$. punctulatus (17.3 per cent) would be unusually high for conspecifics, according to previous studies on insects. Furthermore, a comparison of sequence divergence in mitochondrial rRNA genes among other cockroach species revealed that the observed level of sequence divergence among $C$. punctulatus individuals is comparable to that among congeneric species. Kambhampati (1995), in a study of cockroach phylogenetics, included multiple species of two genera, Blaberus and Periplaneta. The overall sequence divergence among four species of Blaberus for homologous fragments of the 12S rRNA and 16S rRNA genes was 9.7 per cent, with a mean $( \pm S E)$ Kimura 2-parameter distance of $0.053 \pm 0.02$; the corresponding figures for four species of Periplaneta were 16.0 per cent and $0.095 \pm 0.008$, respectively. For the $C$. punctulatus individuals we sampled, the overall sequence divergence was 17.3 per cent with a mean Kimura distance of $0.062 \pm 0.003$. The sequence divergence among individuals in 12 eastern locations was 13.5 per cent with a mean Kimura 2-parameter distance of $0.049 \pm 0.003$, figures comparable to those among the four species of Blaberus. The corresponding figures for the individuals in five Oregon locations were 1.7 per cent and $0.009 \pm 0.002$, respectively. It is clear that the genetic divergence among the eastern and the western $C$. punctulatus individuals and among individuals in eastern USA is comparable to that found among congeneric species of other cockroaches. Thus, the DNA sequence data are strongly suggestive of multiple sibling species of $C$. punctulatus in the USA. It is difficult to assign species status based strictly on mtDNA divergence. However, individuals from North Carolina (other than the one from Asheville), Georgia and Alabama formed a rather homogenous group, whereas those from Virginia have clearly diverged from individuals in the above locations. The individual from Asheville was not grouped with the others from North Carolina; this is not surprising as its chromosome number differed not only from other North Carolina individuals, but from all eastern individuals. Further studies are needed to clarify the taxonomic status of the population(s) in the Asheville region. Additionally, it would be important to determine if individuals from two other North Carolina locations, Crossnore and Todd, which had $2 n=43$, are similar in their mtDNA to individuals from Virginia with the same chromo- some number. The individuals sampled in Oregon showed $<2$ per cent sequence divergence, a level consistent with that found among conspecifics, based on previous studies on insects (see above). The Oregon individuals, however, have diverged significantly from those in eastern USA and probably constitute a species distinct from individuals in eastern USA.

\section{Karyotype variation}

Variation in chromosome number similar to that seen in $C$. punctulatus has also been reported for other animals, e.g. the beetle Chilocorus, the mollusc Thais, the marine isopod Jaera, the shrew Sorex and several morabine grasshopper species (see also White, 1978 and King, 1993 for additional examples). The phenomenon is more common in animals with highly structured and localized populations, low vagility and probably significant inbreeding. The variation in chromosome number in such cases often results from Robertsonian fusions or fissions (White, 1978). Where this kind of variation is found, it is often difficult to determine whether fusions or fissions have predominated. Additionally, it is not always clear whether the variation in chromosome number in such cases reflects chromosomal polymorphism among conspecifics, or the occurrence of sibling species with little or no morphological differentiation. In some beetles and some grasshoppers, hybrids between two chromosomal 'races' are relatively common (White, 1978) suggesting intraspecific polymorphism. In other cases, chromosomal hybrids have not been found, suggesting reproductive isolation. We did not detect any chromosomal hybrids in $C$. punctulatus. They would have been recognized by an even male diploid chromosome number intermediate between the males of the parent karyotypes, and by the presence of multivalents in meiosis. However, the boundaries between different karyotypic populations have not been precisely localized, and no sampling has been undertaken of $C$. punctulatus definitely known to be from such boundaries. Nevertheless, the pattern of variation in rRNA gene sequence and chromosome numbers, and mating studies, suggest considerable restriction, if not the absence, of interbreeding among different chromosomal types.

The difference in chromosome number between the Highlands and Mountain Lake populations of $C$. punctulatus has been shown to be caused by a series of Robertsonian changes involving the autosomes (Luykx, 1983). In place of six small telocentric chromosomes found in the Mountain Lake individ- 
uals $\left(21^{1 \mathrm{II}}+\mathrm{X} ; 2 n \hat{\delta}=43\right)$, three larger metacentric or submetacentric chromosomes were found in the Highlands individuals $\left(18^{\mathrm{II}}+\mathrm{X} ; 2 n \quad \hat{\sigma}=37\right)$. Although the chromosome morphology in all the different karyotypes in this study has not been examined in detail, it is likely that the differences between other $C$. punctulatus populations also involve Robertsonian changes.

The chromosomal differences found in this study, i.e. $23^{\mathrm{II}}+\mathrm{X}, 22^{\mathrm{II}}+\mathrm{X}, 21^{\mathrm{II}}+\mathrm{X}, 19^{\mathrm{II}}+\mathrm{X}$ and $18^{\mathrm{II}}+\mathrm{X}$, suggest an evolutionary series. (The missing karyotype in this series, $20^{\mathrm{II}}+\mathrm{X}$, has not yet been found.) The idea that these karyotypes do indeed represent an evolutionary lineage rather than random chromosomal changes is supported by two observations: the distribution of chromosome numbers appears to be nonrandom in relation to branches of the phylogenetic tree (Fig. 2), and there is a geographical pattern to the distribution of different chromosome number types (Fig. 3). Different chromosome numbers are associated with specific segments of the phylogenetic tree derived from the DNA sequences. All Oregon individuals, which formed a single clade, have $23^{11}+X$. The remainder of the tree is associated with lower chromosome numbers. The first division of Appalachian populations is between Virginia $\left(21^{\mathrm{II}}+\mathrm{X}\right)$ and the more southerly individuals with lower chromosome numbers. The Georgia populations occupy a distinct clade on the tree, with a chromosome number of $19^{\mathrm{II}}+\mathrm{X}$. The Alabama and North Carolina individuals (other than those from Asheville, Crossnore and Todd) form another distinct clade with $18^{\mathrm{II}}+\mathrm{X}$. The data as a whole thus suggest that the splitting of lineages has been accompanied by a reduction in chromosome number as shown in Fig. 2 where the nodes of successively interior branches are associated with successively lower chromosome numbers (circled numbers). The Robertsonian changes have therefore apparently been chromosome fusions rather than fissions. The exceptional Asheville individual could be explained either as a reversal of this trend of repeated fusions or as a relic of a chromosomally ancestral population. In the latter scenario, comparable fusions would have had to have taken place independently in the separate Georgia and North Carolina + Alabama populations. The divergence in both mtDNA genes and chromosomes might be explained in one of two ways. First, when a randomly mating population is chromosomally uniform, genetic similarity in mtDNA is maintained through interbreeding. But a chromosomal variant, once having arisen and become fixed in the homozygous state in a local subpopulation, might lead to reproductive isolation from the parent population. The mtDNA of this newly arisen species, now isolated from the parent population, might be free to diverge by random genetic drift or other mechanisms. Thus, the establishment of a chromosomal variant may promote subsequent divergence in mtDNA. Alternatively, both mtDNA and chromosomal variants may arise by drift or other mechanisms after two populations have become reproductively isolated as a result of some other factors, such as a mutation that affects mate preference or recognition. In this case, both mtDNA and chromosome numbers diverge with time as a result of several reproductive isolation events in succession caused by factors not directly related to either mtDNA or karyotype. Our results suggest that a more extensive sampling of populations in western North Carolina is needed to obtain a clearer picture of the dynamics of chromosomal and mtDNA divergence.

Many theoretical studies have been published on the dynamics of chromosomal evolution and speciation (reviewed by King, 1993). Much of the debate centres around the conditions that can lead to the fixation of negatively heterotic chromosomal variants. In general terms, at least two major mechanisms can lead to the fixation of such variants (King, 1993). First, phenomena such as meiotic drive, position effect and hitchhiking because of linkage with selectively advantageous gene combinations, may override the deleterious effects on fertility of the chromosomal rearrangements. Secondly, stochastic, population-level processes such as random genetic drift, migration and colonization of new territories, may aid in the spread and fixation of novel rearrangements. Lande (1984) concluded that conditions which favour the fixation of negatively heterotic chromosomal rearrangements were small populations with low levels of migration, high rates of local extinction and small effective population sizes. Hedrick \& Levin (1984) found that kin-founding may be a strong factor in the establishment of chromosomal variants in populations. Under conditions in which the population consisted of closely related individuals such as a full-sib group, the probability of fixation of a chromosomal variant, regardless of its effect on fitness, was found to be high. They also suggested that among highly structured populations, groups that consist largely of closely related individuals, such as plants and animals with low dispersal or social animals, should be most susceptible to the fixation of chromosomal variants.

The biology and ecology of Cryptocercus encompass many of the criteria outlined in theoretical studies for populations in which chromosomal rear- 
rangements that may be negatively heterotic have the opportunity to be fixed. These insects live in family groups and thus populations are likely to consist largely of closely related individuals. Immatures and adults of both sexes are wingless and are unlikely to disperse to large distances on their own. Both these conditions, according to theoretical studies (Hedrick \& Levin, 1984; Lande, 1984; see also King, 1993 for additional references), are conducive to the establishment and fixation of chromosomal rearrangements, even if they are negatively heterotic. The theoretical studies mentioned above assume that species have similar rates of chromosomal mutations and rearrangements but vary in their population structure. Because the rates of chromosomal rearrangements are known to vary widely among different groups of organisms (King, 1993), a higher rate of rearrangement, in combination with population structure conducive to the fixation of chromosomal variants, could accelerate the process of fixation of negatively heterotic rearrangements. In addition to the social structure of $C$. punctulatus, its requirement for decaying logs in a forest environment may also have played a role in creating small, highly structured populations (see below).

\section{Mating studies}

An important criterion to consider in determining whether a group of populations constitutes separate species or simply genetically divergent conspecifics is whether or not they are reproductively compatible. Reproductive isolation is a key component of the biological species concept (Mayr, 1942, 1963) and of the cohesion species concept (Templeton, 1989) for delineating species boundaries, because many organisms are known to be genetically divergent without necessarily being reproductively incompatible. 'Chromosomal races' have been reported from a number of organisms (White, 1978; King, 1993). In termites, crosses between different chromosomal races are not necessarily incompatible and may result in the production of viable progeny (Syren \& Luykx, 1981). Our studies on mating compatibility in C. punctulatus are continuing; however, preliminary results strongly indicated the existence of pre- or postmating barriers to reproduction between individuals from Oregon and Virginia. The production of nonviable egg cases in matings between individuals from Virginia and Oregon is consistent with Roth's (1970) study in which he showed that interspecific matings among cockroaches result in the production of nonviable egg cases.
Speciation among the eastern and western populations of Cryptocercus is likely to have been the result of vicariance (Brooks \& McLennan, 1992). Possible speciation among the eastern populations could have been promoted either by habitat fragmentation or by successive and repeated dispersal of individuals from a parental population, as envisioned in the peripheral isolates speciation model (Brooks \& McLennan, 1992). Because Cryptocercus adults are wingless, speciation by dispersal is unlikely. The locations in which Cryptocercus is presently found represent the remnants of a large mesophytic forest that extended throughout much of the northern hemisphere during the Tertiary (Bei-Bienko, 1950; Li, 1952; Mamaev, 1972). Geological events, including mountain elevation, submergence, climatic change and glaciation, resulted in the fragmentation of a previously contiguous forest ( $\mathrm{Li}, 1952)$. Additionally, as shown for the flora of the northern hemisphere (Wood, 1970), the disjunct occurrence of Cryptocercus in eastern and western USA suggests that in the past the genus was distributed widely in that hemisphere. Therefore, it is likely that speciation of Cryptocercus in the USA is a result of habitat fragmentation brought about by geological changes leading to allopatry. Because of the fairly rigid habitat requirements of Cryptocercus for growth and reproduction (see Nalepa, 1994), an unfragmented forest, like the one presently found in the Appalachians, does not necessarily ensure a panmictic population.

In conclusion, karyotype analysis and an analysis of the DNA sequence of portions of the mitochondrial rRNA genes of $C$. punctulatus have revealed significant divergence among individuals collected in different locations of the USA. The evidence from variation in mtDNA sequences and chromosome numbers, and mating studies, leads us to conclude that more than one species of Cryptocercus currently exists in the USA. Specifically, populations in Oregon and the Appalachian Mountains ought to be considered separate species. This conclusion is supported by the failure of crosses between the two to produce viable egg cases and also by the differences in body size, developmental time, gut fauna and cuticular hydrocarbons previously demonstrated between the eastern and Oregon populations (Cleveland et al., 1934; Brossut et al., 1991; C. A. Nalepa, unpublished observations). We have also demonstrated considerable divergence in mtDNA and karyotype among the Appalachian populations themselves; individuals from Virginia have diverged significantly in mtDNA and karyotype from those in southern North Carolina, Georgia and Alabama, 
and may constitute yet another species. Thus, the evidence presented in this study strongly suggests that there are probably at least three species of Cryptocercus in the USA.

\section{Acknowledgements}

We thank R. Zack, B. Bailey, C. Bailey and P. Rand for their help in collecting cockroaches. Field work in Virginia was supported in part by a Mountain Lake Biological Station postdoctoral award to C.A.N., E. P. Catts and Washington State University provided financial support for collections in Oregon; financial support for the DNA studies came from a seed grant from the Department of Entomology, Kansas State University to S.K. We thank D. G. Cochran, P. W. Hedrick and K. Spitze for comments on the manuscript and A. L. Nus for technical assistance. This is journal article no. 95-503-J of the Kansas Agricultural Experiment Station.

\section{References}

ATKINSON, T. H., KOEHLER, P. G. AND PATTERSON, R. S. 1991. Catalog and atlas of the cockroaches of North America north of Mexico. Miscellaneous Publication No. 78. Entomological Society of America, Lanham, MD.

BEI-BIENKo, G.YA. 1950. Blattodea. In: Faune de l'URSS, vol. 40, pp. 332-336. Institute of Zoology, Academy of Sciences URSS, Moscow.

BREMER, K. 1988. The limits of amino acid sequence data in angiosperm phylogenetic reconstruction. Evolution, 42, 795-803.

BREMER, K. 1994. Branch support and tree stability. Cladistics, 10, 295-304.

BROOKS, D. R. AND Mclennan, D. L. 1992. Phylogeny, Ecology and Behavior. University of Chicago Press, Chicago, IL.

BROSSUT, R., NALEPA, C. A., BONNARD, O., LEQUERRE, J. L. AND FARINE, J. P. 1991. Tergal glands of male and female Cryptocercus punctulatus: Composition, sexual dimorphism and geographic variation of the secretion. J. Chem. Ecol., 17, 823-831.

CLEVELAND, L. R., HALL, S. R., SANDERS, E. P. AND COLLIER, J. 1934. The wood-feeding roach Cryptocercus, its protozoa and the symbiosis between protozoa and the roach. Mem. Am. Acad. Arts Sci., 17, 185-342.

COHEN, s. AND ROTH, L. M. 1970. Chromosome numbers of the Blattaria. Ann. Entomol. Soc. Am., 63, 1520-1547.

FANG, Q., BLACK, w. C., IV, BLOCKER, H. D. AND WHITCOMB, R. F. 1993. A phylogeny of nearctic Deltocephalus-like leafhoppers based on mitochondrial $16 \mathrm{~S}$ ribosomal DNA sequences. Mol. Phylogenet. Evol., 2, 119-131.

HEDRICK. P. W. AND LEVIN, D. A. 1984. Kin-founding and the fixation of chromosomal variants. Am. Nat., 124, $789-797$.
HIGGINS, D.M. AND ShARP., P. M. 1989. Fast and sensitive multiple sequence alignment on a microcomputer. Comput. Appl. Biol. Sci., 5, 151-153.

KAMBHAMPATI, s. 1995. A phylogeny of cockroaches and related insects based on DNA sequence of mitochondrial ribosomal RNA genes. Proc. Natl. Acad. Sci. U.S.A., 92, 2017-2020.

KAMBHAMPATI, s. AND SMITH, P. T. 1995. PCR primers for the amplification of four insect mitochondrial gene fragments. Insect Mol. Biol., 4, 233-236.

KAMBHAMPATI, s., BLACK, W. C., IV AND RAI., K. s. 1992. Random amplified polymorphic DNA of mosquitoes: Techniques, applications and statistical analyses. J. Med. Entomol., 29, 939-945.

KIMURA, M. 1980. A simple method for estimating evolutionary rate of base substitutions through comparative studies of nucleotide sequences. J. Mol. Evol., 6, $111-120$.

KING, M. 1993. Species Evolution: The Role of Chromosome Change. Cambridge University Press, Cambridge, UK.

Kumar, s., TAMURA, K. AND NeI, M. 1993. MEgA: Molecular evolutionary genetic analysis. Version 1.01. Institute of Molecular Evolution, Pennsylvania State University, University Park, PA.

LANDE, R. 1984. The expected fixation rate of chromosomal inversions. Evolution, 38, 743-752.

LI, H.-L. 1952. Floristic relationships between eastern Asia and eastern North America. Trans. Am. Phil. Soc., 42, 371-429.

LUYKX, P. 1983. XO:XX sex chromosomes and Robertsonian variation in the autosomes of the wood-roach Cryptocercus punctulatus (Dictyoptera: Blattaria: Cryptocercidae). Ann. Entomol. Soc. Am., 76, 518-522.

MAMAEV, B. M. 1972. Ecology of the relict cockroach (Cryptocercus relictus). Ekologiya, 4, 70-73.

MCKITTRICK, F. A. 1964. Evolutionary studies of cockroaches. Cornell Univ. Ag. Exper. Stat. Mem., 389, 1-197.

MAYR, E. 1942. Systematics and the Origin of Species. Columbia University Press, New York.

MAYR, E. 1963. Animal Species and Evolution. Harvard University of Press, Cambridge, MA.

NALEPA, C. A. 1988. Cost of parental care in the woodroach, Cryptocercus punctulatus Scudder (Dictyoptera: Cryptocercidae). Behav. Ecol. Sociobiol., 23, 135-140.

NALEPA, C. A. 1994. Nourishment and the origin of termite eusociality. In: Hunt, J. H. and Nalepa, C. A. (eds) Nourishment and Evolution in Insect Societies, pp. 57-104. Westview Press, Boulder, CO.

ROTH, L. M. 1970. Interspecific mating in Blattaria. Ann. Entomol. Soc. Am., 63, 1282-1285.

SAITOU, N. AND NEl, M. 1987. The neighbor-joining method: a new method for reconstructing phylogenetic trees. Mol. Biol. Evol., 4, 406-425.

simon, C. 1991. Molecular systematics at the species boundary: exploiting conserved and variable regions of the mitochondrial genome of animals via direct sequencing from amplified DNA. In: Hewitt, G. M., Johnson, A. W. M. and Young, J. P. W (eds) Molecular Techniques in Taxonomy, pp. 33-72. NATO ASI Series 
H57, Springer, Berlin.

SIMON, C., FRATI, F., BECKENBACH, A., CRESPI B., LIU H. AND FLOOK, P. 1994. Evolution, weighting and phylogenetic utility of mitochondrial gene sequences and compilation of conserved polymerase chain reaction primers. Ann. Entomol. Soc. Am., 87, 651-701.

SwOFFORD, D. L. 1993. PAUP: Phylogenetic Analysis Using Parsimony. Version 3.1.1. Smithsonian Institution, Washington, DC.

SYREN, R. M. AND LUYKX, P. 1981. Experimental hybridization between chromosomal races in Kalotermes approximatus, a termite with extensive sex-linked translocation heterozygosity. Chromosoma, 83, 563-573.
TEMPLETON, A. 1989. The meaning of species and speciation: a genetic perspective. In: Otte, D. and Endler. J. A. (eds) Speciation and its Consequences, pp. 3-27. Sinauer Associates, Sunderland, MA.

white, M. J. D. 1978. Animal Cytology and Evolution, 3rd edn. Cambridge University Press, Cambridge, UK.

wOOD, C. E., JR. 1970. Some floristic relationships between the southern Appalachians and western North America. In: Holt, P. C. and Patterson, R. A. (eds) The Distributional History of the Biota of the Southern Appalachians. Part II. Flora, pp. 33-45. Research Division Monograph 2, Virginia Polytechnic Institute and State University, Blacksburg, VA. 